ARTIGOS 


\title{
Interculturalidade e o papel da escola na atualidade: reflexões a partir do filme Entre os muros da escola
}

Flaviana Gasparotti Nunes ${ }^{*}$

Resumo: Considerando a importância que questôes como a diversidade cultural e a identidade têm apresentado para a reflexão sobre o papel da escola nos dias atuais, procuramos, neste texto, desenvolver algumas ideias referentes a esta problemática com base nos elementos trazidos por Laurent Cantet no filme Entre os muros da escola. A opção por discutir a questão a partir dos elementos e das situaçôes de uma obra cinematográfica justifica-se por entendermos a relevância que o cinema, enquanto linguagem, adquire, no sentido de expressar visóes, sentidos e reflexões sobre as questóes colocadas para a sociedade. Sendo assim, procuramos discutir, a partir de passagens do filme, como Cantet utiliza o microcosmo da sala de aula e da escola, destacando seus "muros" como metáfora para pensar a própria sociedade. Apontamos como um dos desdobramentos consequentes da problemática abordada por Cantet a relevância das propostas de educação intercultural para repensar o papel da escola na atualidade.

Palavras-chave: interculturalidade; identidade; diversidade cultural; escola; linguagem cinematográfica.

Interculturality and the school role today: reflections on the movie "The Class" (original title: Entre les Murs)

\begin{abstract}
We take into consideration the importance that issues such as cultural diversity and identity have risen for the reflection on the role of the school today. Hence, in this text, we try to develop some ideas regarding this topic based on the elements brought by Laurent Cantet in the film "The Class". The option to discuss this question through elements/situations from a cinematographic piece of work is justified by the fact that we understand the relevance of the cinema as a language in expressing views, meanings and reflections on questions posed to society. Therefore, we try to discuss the way Cantet uses the microcosm of the classroom and of the school, highlighting their "walls" as a metaphor, so as to think about the society itself. We point out, as a result of the issues approached by Cantet, the relevance of the intercultural education proposals in order to rethink the role of the school today.
\end{abstract}

Key words: interculturality; identity; cultural diversity; school; cinematographic language.

Professora da Universidade Federal da Grande Dourados (UFGD), MS, Brasil. flaviananunes@ ufgd.edu.br 


\section{Introdução}

Considerando a importância que questôes como a diversidade cultural e a identidade têm apresentado para a reflexão sobre o papel da escola nos dias atuais, neste texto ${ }^{1}$ procuramos desenvolver algumas ideias referentes a esta problemática, com base nos elementos trazidos por Laurent Cantet ${ }^{2}$ no filme Entre os muros da escola ${ }^{3}$.

O filme foi vencedor da Palma de Ouro no Festival de Cannes em 2008 e é baseado no livro homônimo de François Bégaudeau, que retrata a experiência de um professor ginasial - o próprio autor - e suas dificuldades para ensinar Língua Francesa numa escola da periferia de Paris ${ }^{4}$.

A opção por discutir essa problemática a partir dos elementos e das situações de uma obra cinematográfica justifica-se por entendermos a relevância que o cinema, enquanto linguagem, tem adquirido, no sentido de expressar visões, sentidos e reflexões sobre as questóes colocadas para a sociedade. Podemos dizer que os filmes revelam o olhar de uma época ou de uma sociedade, na medida em que, além de expressarem visões das pessoas envolvidas em sua montagem, indiretamente revelam

[...] o imaginário de seus espectadores, pois antes mesmo de vir a contribuir na formação e reforço de hábitos culturais, a produção de um determinado filme leva em conta a visão de seu público alvo, seu universo de referências, conhecimentos e expectativas. [...] (Oliveira, 2006, p. 141)

Além disso, não podemos deixar também de lembrar as críticas e os debates atualmente estabelecidos acerca dos limites da construção do conhecimento, pautados nos referenciais da ciência moderna e, consequentemente, na linguagem que esse tipo de conhecimento produziu para expressá-la. Sobre esta questão, Hissa (2006, p. 28-29, grifo do autor) afirma:

I. Agradeço ao Prof. Charlei Aparecido da Silva a oportunidade de debater este filme, o que me motivou a elaborar o presente artigo.

2. Laurent Cantet, diretor de cinema francês, possui uma obra voltada a discussões de caráter sociopolítico, expressas em filmes como Recursos humanos ( 1999) e A agenda (200 I).

3. Este foi o título do filme no Brasil. O título original do filme é Entre les murs. Direção de Laurent Cantet e roteiro de François Bégaudeau, Robin Campillo e Laurent Cantet. França. 128 min. 2008. Distribuição: Imovision/Sonopress.

4. Uma das peculiaridades em relação ao filme é que foi rodado em um colégio do leste de Paris e seu elenco é formado, em sua maioria, por não atores. Além disso, por vezes apresenta certo caráter de documentário, tendo em vista os posicionamentos de câmeras e os próprios diálogos estabelecidos entre os personagens.

Pro-Posiçóes, Campinas, v. 22, n. 3 (66), p. 113-129, set./dez. 2011 
[...] O produto convencional da ciência do rigor excêntrico já nasce estéril e, além disso, elimina as possibilidades de ampliação de uma leitura criativa. A ciência, assim, limitarse-ia ao dado coletado do mundo, como se ele pudesse ser o mundo. Além disso, a leitura do dado - mesmo contando com seus limites - já seria impossibilitada pela ansiedade do rigor: não se poderia indagar a procedência e o destino do dado. O excêntrico rigor da ciência, caricaturado por Borges, termina por reduzir o valor do saber enquanto instrumento de crítica, de imaginação e de transformação. A ciência moderna, na busca da objetividade, quanto mais expande seus limites, mais reduz o universo da crítica e da criatividade. Não há interpretação, tampouco simbologia. A reprodução atua como última fronteira do despropósito.

Na opinião de Hissa, o rigor da ciência moderna reduz as possibilidades de criatividade, interpretação e simbologia. Tais limites, que tomam por base a centralidade do método, expressam-se enquanto linguagem nas produções textuais resultantes desse método. É nesse sentido que o diálogo da ciência com outras formas de produção do conhecimento é cada vez mais solicitado. Nesse caso, o diálogo com as artes aponta possibilidades de ampliação dos limites da linguagem científica.

Podemos considerar o cinema, concebido como obra de arte e linguagem, um importante instrumento analítico da contemporaneidade, conforme aponta Costa (2009, p. 110):

O cinema tem sido crescentemente explorado e valorizado como instrumento analítico na contemporaneidade. $\mathrm{O}$ enfoque no contexto cinemático como representação e suporte para a análise dos grupos culturais e do cotidiano dos indivíduos participantes desses grupos nos espaços urbanos tornou-se primordial para o entendimento dos modos, da coerência e do sentido pelos quais vivências, comportamentos, identidades, subjetividades e práticas socioculturais vêm sendo constituídos, entendidos e reelaborados espacialmente e subjetivamente.

O potencial analítico e reflexivo sobre a realidade, propiciado pelo cinema, permite transgredir os limites impostos pela linguagem científica, na medida em que "[...] uma árvore, num filme, é tanto aquela árvore, como pode ser, também, alegoria para a natureza; um homem é tanto aquele que está ali na tela, quanto pode ser também toda a humanidade. Essa é a potência dos filmes e que agora vem chamando a atenção [...]" (Queiroz Filho, 2009, p. 47). 
As palavras do autor permitem-nos pensar, portanto, que a linguagem cinematográfica possibilita simbologias, metáforas e analogias no sentido criticado por Hissa, já citado anteriormente. Dessa forma,

[...] os filmes são produções em que a imagem em movimento, aliada às múltiplas técnicas de filmagem e montagem e ao próprio processo de produção e ao elenco selecionado, cria um sistema de significaçôes. Quando dizemos que o cinema cria um mundo ficcional, precisamos entendê-lo como uma forma de a realidade apresentar-se. (Fabris, 2008, p. 118)

Tendo em vista o exposto, acreditamos que a reflexão sobre o papel da escola na atualidade pode ser ricamente potencializada pelas imagens, pelos diálogos, pelos personagens e por toda a narrativa construída por Laurent Cantet em sua obra cinematográfica, permitindo que, a partir dela, o discurso científico sobre essa questão seja ampliado.

\section{O cenário da escola/sociedade: diversidade cultural e identidade em questão}

Vivemos em sociedades que, marcadas pela pluralidade de culturas e por formas diferenciadas de apreensão do mundo, caracterizam-se por processos de identificação grupal que se constituem muito além de uma única ideia de cultura e da consequente assimilação por parte de grupos diferenciados.

É nesse contexto que surgem as discussões referentes ao multiculturalismo como conjunto de ideias e processos que visam o reconhecimento da diversidade cultural, assim como a extinção de qualquer forma de preconceito derivado de diferenciaçôes identitárias ou culturais. De acordo com Souza Santos e Nunes (2003, p. 26, grifos dos autores):

A expressão multiculturalismo designa, originalmente, a
coexistência de formas culturais ou de grupos caracterizados
por culturas diferentes no seio de sociedades "modernas".
Rapidamente, contudo, o termo se tornou um modo de
descrever diferenças culturais em um contexto transnacional
e global.

Sendo assim e considerando a afirmação de Candau (2008, p.13) de que "[...] não há educação que não esteja imersa nos processos culturais do contexto em que situa [...] não é possível conceber uma experiência pedagógica 'desculturalizada', isto é, desvinculada das questões culturais da sociedade. [...]", acreditamos que pensar sobre o papel da escola nos dias atuais implica, necessariamente, colocar na ordem do dia o debate sobre essas questôes. 
Este é, sem dúvidas, um grande desafio para os professores, que se veem diante da necessidade de conciliação dos diferentes significados e símbolos das culturas, ao mesmo tempo que tentam impor-se perante as necessidades educacionais, seus objetivos e ações (Werneck, 2008, p. 417).

A escola é um espaço carregado de diferentes formas e simbolismos culturais marcados pela diversidade de pessoas que ali convivem. Nesse sentido, torna-se necessário refletir sobre as práticas educacionais que são desenvolvidas no seu interior, de forma que estas busquem trabalhar com as diferenças existentes e com as relações de identificação e diferenciação que ocorrem não apenas em seu interior, mas que se estendem externamente, refletindo diretamente nas práticas sociais desenvolvidas pelos sujeitos em suas relaçóes cotidianas.

Ao discutir a função e o papel desempenhados pela escola, é inevitável pensar nos elementos culturais presentes de diferentes formas em seu interior e também em sua função como instituição de um Estado, estando a ele ligada, respondendo a determinados interesses e seguindo normas estipuladas.

Embora, historicamente, a escola tenha sido utilizada como instrumento veiculador de uma ideologia nacional e também da existência de uma cultura e uma identidade que remetem a uma determinada nação, partimos da premissa de que, em seu interior, há um entrecruzamento de culturas, inclusive dentro de um mesmo país, pois a cultura é algo amplo, que vai além de delimitações de ordem físico-territorial.

Para Souza Santos e Nunes (2003, p. 27), existem dois modos de definir a cultura: de um lado, ela está associada a um dos campos do saber institucionalizados no Ocidente - as humanidades -, sendo definida como um repositório do que de melhor foi pensado e produzido pela humanidade, baseado em critérios de valor, estéticos, morais ou cognitivos que, definindo-se a si próprios como universais, omitem a diferença cultural ou a especificidade histórica dos objetos que classificam. De outro lado, há uma concepção que reconhece a pluralidade de culturas, definindo-as como totalidades complexas que se confundem com as sociedades, permitindo caracterizar modos de vida fundados em condições simbólicas e materiais. Na opinião dos autores, esses dois modos de definir a cultura permitem estabelecer uma distinção entre as sociedades modernas, as quais coincidem com os espaços nacionais e com os territórios sob autoridade de um Estado - que têm cultura -, e as outras sociedades pré-modernas ou orientais, que são cultura. Instituições típicas da modernidade ocidental, como as universidades, o ensino obrigatório, os museus e outras organizações foram responsáveis por consagrar e reproduzir essas duas formas de conceber a cultura que foram exportadas para os territórios coloniais ou para os novos países emergentes dos processos de descolonização, reproduzindo nesses contextos concepções eurocêntricas de universalidade e diversidade.

É possível verificar, portanto, que a ideia de cultura associada às delimitações de ordem físico-territorial se relaciona aos limites territoriais dos Estados-Nação. 
A cultura, dessa forma, seria associada às manifestações circunscritas aos limites estabelecidos pelo Estado-Nação.

No entanto, entendemos que a cultura se caracteriza como um fator criador de símbolos que darão significado à vida das pessoas, perpassando os aspectos econômicos e políticos. Há, no interior de um país, uma variedade de culturas em pequenas e grandes escalas, que fogem à homogeneidade de uma escala nacional.

Bhabha (2005, p. 65), ao problematizar as noções de diversidade cultural e diferença cultural", optando pela segunda, afirma que "[...] nenhuma cultura é jamais unitária em si mesma, nem simplesmente dualista na relação do Eu com o Outro. [...]". Dessa forma, o autor salienta que as reinvindicações hierárquicas de originalidade ou "pureza" inerentes às culturas são insustentáveis, mesmo antes de recorrermos a instâncias históricas empíricas que demonstram seu hibridismo, pois todas as afirmações e os sistemas culturais são construídos nesse espaço contraditório e ambivalente da enunciação.

Nesses termos, as reflexões sobre o(s) significado(s) da cultura possuem estreita relação com a reflexão sobre a questão da identidade. Segundo Gabriel (2005, p. 50), a concepção essencialista de identidade e de cultura está na base da proposta hegemônica do projeto da modernidade. Para a autora:

Essa concepção sugere que existe um conjunto cristalino de características de que todos os membros partilham, podendo ser reivindicadas como verdadeiras e genuínas. A identidade assim concebida faz apelo a uma suposta qualidade essencial, que permaneceria imutável ao longo do tempo. (Gabriel, 2005, p. 50)

Tais questões tornam-se fundamentais para a reflexão sobre o papel da escola no atual contexto social. Para Gabriel (2005, p. 39):

Espaço privilegiado de produção de identidades e diferenças, a escola tende hoje a ser questionada - tanto em termos de seus fundamentos como de suas funções e funcionamento - nos debates em torno do que tem sido identificado como uma das marcas da nossa contemporaneidade: a crise da identidade.

Com efeito, essa crise, apreendida como um momento da trajetória de construção/desconstrução do projeto de moder-

5. Para o autor, a diversidade cultural é entendida como objeto epistemológico, na medida em que a cultura é vista como objeto do conhecimento empírico. Já a diferença cultural é o processo de enunciação da cultura como conhecível, legítimo, adequado à construção de sistemas de identificação cultural, é um processo de significação através do qual afirmações da cultura ou sobre a cultura diferenciam, discriminam e autorizam a produção de campos de força, referência, aplicabilidade e capacidade.

Pro-Posiçóes, Campinas, v. 22, n. 3 (66), p. 113-129, set./dez. 2011 
nidade (Santos, 2000), traz implicações que se fazem sentir também nas práticas pedagógicas cotidianas, interferindo direta e indiretamente na apreensão dos elementos e das dimensões que constituem os processos de ensino-aprendizagem desenvolvidos no âmbito escolar.

As questões até aqui pontuadas são evidenciadas com muita clareza por Cantet em seu filme. O microcosmo da sala de aula do professor François Marin, personagem central do filme, expressa a diversidade de culturas e as possibilidades de construçôes identitárias da França atual. A sala de aula é repleta de estudantes das mais variadas origens, com os mais diferentes interesses. São marcantes a presença das diferenças sociais e o choque entre as culturas africana, árabe, asiática e europeia, dentro das quatro paredes da sala de aula.

O professor, por sua vez, de origem francesa, tenta ensinar literatura e artes ocidentais. Pode-se dizer que há uma diferença cultural e social que gera incompreensão e atrito entre ambas as partes, em um retrato do que seria a França contemporânea. O professor se esforça em fazer com que seus alunos de diferentes etnias incorporem o idioma francês imposto a eles. Nesse sentido, a linguagem é o grande campo de batalha onde é travado esse conflito cultural. O diálogo que transcrevemos a seguir, que ocorre por volta de $11 \mathrm{~min} 22 \mathrm{~s}$ do filme, expressa de forma clara esta questão: durante a aula de Língua Francesa, o professor François está discutindo o significado da palavra "suculento" e utiliza a seguinte frase para exemplificar o uso da palavra: "Bill delicia um suculento cheeseburguer. "Após uma série de comentários dos alunos sobre o cheeseburguer (se é ou não bom), entre outros elementos que tangenciam a discussão sobre o significado de "suculento", objetivo central do professor naquele momento, trava-se o diálogo a seguir entre o professor e as alunas Khoumba e Esmeralda e, ao final, Souleymane:

Khoumba: E por que sempre bota esse Bill?

François: Assobio?

Khoumba: Assobio não. Esse Bill aí. Sempre coloca nomes esquisitos...

François: Não é esquisito. É o nome de um presidente recente dos EUA, lembra?

Khoumba: Por que não bota Ä̈ssata ou Rachid ou Ahmed?

Esmeralda: Sempre coloca nomes coxinhas.

François: Nomes o quê?

Esmeralda: Coxinhas.

François: Coxinhas como? 
Esmeralda: Coxinhas... Nomes franceses.

François: Você não é francesa?

Esmeralda: Não, não sou francesa.

François: Ah, não? Eu não sabia.

Esmeralda: Eu sou, mas não tenho orgulho de ser.

François: Eu também não. Também não tenho orgulho de ser francês.

Khoumba: Por que o senhor sempre escolhe nomes assim?

François: Olhe, Khoumba, escolher os nomes em função da origem de cada aluno é impossivel.

Esmeralda e Khoumba: Pode mudar um pouco!

Souleymane: É... Chega de Bill, Bob...

François: Qual vocês sugerem?

Souleymane: Bintu.

Khoumba: Aissata!

O questionamento levantado pelas alunas Khoumba e Esmeralda acerca dos nomes de pessoas utilizados pelo professor François em seus exemplos na aula de Língua Francesa expressa a distância entre os conteúdos trabalhados na escola e a realidade vivida pela maioria dos alunos daquela turma. Grande parte deles, bem como seus familiares e amigos, possuem nomes não "coxinhas", como diz a gíria utilizada pela aluna Esmeralda para referir-se a nomes franceses, que podemos entender também como nomes ocidentais. O professor alega ser difícil escolher os nomes em função da origem de cada aluno, mas as alunas dizem: "Pode mudar um pouco!".

O sentido de "mudar um pouco" relaciona-se justamente à necessidade de repensar a concepção monocultural e homogeneizadora que embasa as construções curriculares da escola. Para Candau (2008, p. 15),

[...] esta consciência do caráter homogeneizador e monocultural da escola é cada vez mais forte, assim como a consciência da necessidade de romper com esta e construir práticas educativas em que a questão da diferença e do multiculturalismo se façam cada vez mais presentes.

A autora salienta, ainda, uma nova compreensão das relações entre educação e cultura(s), que se relaciona a uma concepção de escola como um espaço de cruzamento de culturas, fluido e complexo, atravessado por tensões e conflitos.

Em seu entendimento, é fundamental que sejamos capazes de desenvolver currículos que incorporem referentes de universos culturais diversos, coerentes com 
a perspectiva intercultural ${ }^{6}$. Assim, trabalhar o cruzamento de culturas na escola constitui-se também uma exigência que está intimamente associada a ela.

Ao discutir os desafios da diversidade na escola, Gusmão (2003, p. 94) afirma que o que está em jogo em nossas práticas e propostas educativas, mais que as diferenças e a imensa diversidade que nos informa, é a alteridade, espaço permanente de enfrentamento, tensão e complementaridade:

[...] Nessa medida, a escola, mais que um espaço de socialização, torna-se um espaço de sociabilidades, ou seja, um espaço de encontros e desencontros, de buscas e de perdas, de descobertas e de encobrimentos, de vida e de negação da vida. A escola por essa perspectiva é, antes de mais nada, um espaço sociocultural. (Gusmão, 2003, p. 94)

Ao pensarmos na alteridade apontada por Gusmão (2003), inevitavelmente, teremos que discutir a questão da identidade nesse contexto. Tal problemática também é discutida de forma contundente por Cantet no filme. Por volta de $1 \mathrm{~h} 13 \mathrm{~min}$ ocorre uma cena na sala de aula: o professor François desenvolve uma atividade em que solicita que cada aluno vá à frente da sala e faça um discurso como se fosse um político, convencendo as pessoas de algo. O aluno Nassim, marroquino, vai à frente e inicia o diálogo:

Nassim: A Copa das Naçôes Africanas já vai começar.

Alguém diz: Copa das Naçóes Africanas? Essa não...

Nassim: Adorei que o Marrocos vai jogar. É o melhor time do mundo, na minha opinião. Só fiquei chateado porque os malineses não vão jogar. Foi duro pra eles. Eles não conseguiram se classificar. Se o Marrocos tivesse jogado amigavelmente, mas 4 a 0 foi doido.

François: Como assim 4 a 0 ?

Nassim: Porque Mali jogou contra o Marrocos e tomou de 4 a 0. Mas tem uma coisa engraçada, o dia em que o Mali não joga, todos os negros que vivem aqui, os africanos, deixam de ser africanos. Porque, quando tem Copa da África, eles ficam malucos, mas quando o Mali não joga, eles ficam de boa, nem ligam. É engraçado.

François: Certo... o fato do Mali jogar ou não jogar na Copa da África deixa os africanos da classe mais ou menos africanos.

6. No texto em questão, Candau (2008) expõe as diferentes abordagens do multiculturalismo e assume a perspectiva que propõe um multiculturalismo aberto e interativo, que acentua a interculturalidade por considerá-la mais adequada para a construção de sociedades democráticas, pluralistas e inclusivas, que articulem políticas de igualdade com políticas de identidade. 
$E$ isso?

Nassim: Certo.

François: Obrigado, Nassim. Tive a impressão de que mandou um recado para o Souleymane.

Souleymane: Não registro o que esse marroquino fala.

Na sequência do filme, por volta da $1 \mathrm{~h} 15 \mathrm{~min} 50$ s, outro aluno (Boubacar) vai à frente da sala fazer seu discurso:

Boubacar: Eu vim aqui responder pro Nassim. Ele disse que, como o Mali ficou fora da Copa, os africanos ficaram sem ter pra quem torcer. A gente não pode esquecer da Costa do Marfim. Eles têm um astro no time: o Didier Drogba. Ele dá de dez em todos os marroquinos!

[Nassim dá risada]

Boubacar: Que foi?

Nassim: Vai, fala...

Boubacar: Didier Drogba joga no Chelsea. Que marroquino joga na Inglaterra? Que marroquino joga na Inglaterra? Nenhum deles presta e vem se gabar!

Outro aluno (Carl) vai à frente fazer o seu discurso e fala:

Carl: Eu queria dizer que eles não param de encher o saco com essa Copa da Árica. Lá no pátio já estavam enchendo o saco dos outros com essa Copa e ela nem começou ainda!

Boubacar: Carl? Vou ser bem educado com você.

Carl: Pode falar.

Boubacar: Desculpe interromper. Pode dizer pra que seleção você torce?

Carl: França.

Boubacar: Espera aí! E por que você diz que não é francês, que é antilhano?

Carl: Antilhanos são franceses. Lá é um território francês.

Boubacar: E por que não diz "somos franceses" e diz "somos antilhanos"?

Carl: Dá na mesma.

Boubacar: Eu não acho.

Carl: Olha só os jogadores: o Thierry Henri, o Wiltord, o Abidal, o Thuram.

Souleymane: E o Diarra? Onde ele joga?

Pro-Posiçôes, Campinas, v. 22, n. 3 (66), p. 113-129, set./dez. 2011 
Carl: Esse nunca vai jogar no Mali, meu irmão.

Souleymane: Cala a boca, cara! Não sou irmão de um macaco burro como você!

Antilhano de merda!

Acreditamos que as falas das personagens aqui transcritas possuem significados e sentidos extremamente ricos para a reflexão sobre alteridade e identidade e sobre a forma como estas têm se revelado na escola. Nassim, que é marroquino, provoca outros colegas também africanos, mas de origem malinesa, utilizando o futebol como elemento que desperta a "identidade nacional" - se o Mali não joga, a identidade africana não é destacada ou não existe. Ao mesmo tempo, Boubacar tenta questionar a "superioridade marroquina" apregoada por Nassim, levantando o fato de não haver jogadores desse país em times de destaque mundial, diga-se europeus, como o Chelsea da Inglaterra, ao passo que a Costa do Marfim possui.

Quando Carl coloca em questão a irrelevância da discussão sobre o assunto, Boubacar o questiona sobre sua identidade: é francês ou antilhano? Carl diz que isso não faz diferença e aponta os importantes jogadores que a seleção francesa possui, em detrimento dos jogadores do Mali. Souleymane, que é malinês, imediatamente o chama de "macaco burro" e "antilhano de merda".

Fica claro, a partir dessas falas, que, devido às diferenças de origem, em dados momentos de confronto verbal entre os alunos, eles reproduzem certas concepções colonialistas europeias, estabelecendo diferenciações nacionais e culturais hierárquicas, embora estejam em um mesmo contexto social de filhos de imigrantes ou sejam, eles mesmos, imigrantes (Eduardo, 2009).

Além disso, a tensão estabelecida e os constantes ataques de fundo depreciativo a determinadas origens culturais entre os alunos colocam em questão o próprio significado da identidade pautada nos referenciais do Estado-Nação. Todos vivem na França e estudam a língua francesa, numa escola francesa. Mas o que significa, de fato, "ser francês" no atual contexto social? Esta parece ser uma das questôes centrais abordadas por Cantet, que emergem "entre os muros da escola". Mas a escola em si não é o foco principal do filme. Na sequência, procuraremos discutir esta afirmação de forma mais verticalizada.

\section{Para pensar "além dos muros" da escola e da sociedade}

Cantet utiliza o microcosmo da sala de aula e da escola, destacando seus "muros" como metáfora para pensar a própria sociedade, fato evidenciado pelo título original do filme: Entre muros.

Os muros da escola não são os únicos que revelam uma divisão e uma impenetrabilidade entre dois lados. Há também outros muros invisíveis sugeridos no 
filme (Saçashima, 2009). A escola, neste caso, reflete a própria sociedade. Reflete tensōes dessa sociedade, e Cantet prefere introjetá-las nos limites concretos de uma escola para, na verdade, referir-se a esse universo social de modo mais amplo.

Coloca-se, de certa forma, mais uma vez o papel da escola em questão: é reflexo, reprodução ou alternativa para superação da sociedade na qual está inserida? Qual sua função numa sociedade marcada pela diversidade sociocultural, num mundo que questiona os referenciais da sociedade moderna ocidental? Gabriel (2008, p. 213-215) caracteriza este momento como "tempos pós":

[...] Tempos de uma nova ordem de acumulação de capital, de uma nova lógica cultural, da centralidade da linguagem na produção do mundo "em significados", da crítica radical a uma racionalidade moderna pautada em noçốes de objetividade, verdade, universalidade que, embora estejam sendo problematizadas e questionadas, ofereceram, até a época recente, os parâmetros para a elaboração de grades de inteligibilidade do mundo socialmente legitimadas.

Tempos de escola "sob suspeita", em que a questão da produção dos saberes nos remete diretamente às problemáticas $\mathrm{da}$ verdade, da racionalidade e da objetividade do conhecimento no processo de legitimação dos conteúdos considerados válidos a serem ensinados e aprendidos. [...]

Tempos pós em que a condição (da escola), de estar "sob suspeita", significa que não foi demonstrada ainda a extensão de sua responsabilidade na construção do projeto de uma modernidade que apresenta nítidos sinais de esgotamento e, portanto, não nos autoriza a negar radicalmente a potencialidade dessa instituição em significar e agir no e sobre o mundo. [...]

Ao afirmar que a escola está "sob suspeita", a autora questiona sua função, tendo em vista que o próprio projeto societário no qual ela foi concebida mostra sinais de esgotamento. Esta questão é evidenciada por Cantet nas várias situações do filme: nas aulas de François com sua turma; nas conversas dos professores na sala dos professores; nas reunióes do conselho da escola. A questão de fundo parece sempre ser: ensinar o quê, para quem e para quê? Este parece ser o dilema vivido pelos professores, bastante evidente nas situações protagonizadas por François.

Este, por sua vez, ao propor aos alunos a elaboração de autorretratos, tenta desenvolver procedimentos didáticos e, mesmo, concepçóes de ensino e conhecimento que possam romper os limites da escola formal, numa aproximação mais humanizada com os alunos. No entanto, tal procedimento se desenvolve num contexto em que as concepções majoritárias são incompatíveis com essa proposição. 
Isso se revela, por exemplo, nas posturas fúteis e superficiais de alguns professores e na discussão sobre formas de punição aos alunos.

Ao destacar o questionamento do papel da escola na sociedade atual, Cantet discute, de fato, qual sociedade é essa em que vivemos. E alerta que a escola, tal como se apresenta, é incompatível com as demandas da sociedade atual. O olhar do professor, o papel dos conhecimentos científicos e de uma cultura ocidental são questionados e devem ser repensados para a definição da escola e de seu papel na sociedade.

Para Tedeschi (2008, p. 16):

O paradoxo atual da educação e da escola como sua guardiã é que justamente uma instituição que objetivava, até há algum tempo, "construir uma cidadania universal" e homogênea, agora, se vê obrigada a reconhecer as diferenças religiosas, culturais, sexuais ou étnicas locais... Como pensar essa escola que formará cidadãos com uma identidade cultural histórica e local e que, ao mesmo tempo, proporcione a seus alunos a possibilidade de estabelecimento de contato e intercâmbio com outras culturas? Como iniciar na escola um processo de reconhecimento mútuo? [...]

Nesse sentido, um dos desdobramentos consequentes da problemática apontada por Cantet refere-se à relevância das propostas de uma educação intercultural. A educação multi/intercultural tem por objetivo a promoção de práticas entre os alunos e os professores, visando à ruptura de processos de negação do outro e também de uma busca por direitos humanos igualitários para todos os grupos sociais e culturais, mas uma igualdade que não implique seu anulamento e hierarquização.

Segundo Tedeschi (2008, p. 16-17), mesmo considerando o quadro problemático relativo aos aspectos social e educativo e aos fatores culturais e econômicos, é possível perceber algumas açôes e reflexôes que indicam um gestar de uma prática educativa baseada no reconhecimento mútuo e na convivência democrática. Para o autor: "Ao se considerar a interculturalidade como uma perspectiva enriquecedora das práticas educativas, estamos considerando a educação como um processo universal de aprendizagem de várias lógicas, baseada na comunicação e na troca permanente entre diferentes. [...]" (Tedeschi, 2008, p. 17).

Sendo assim, além de contemplar questóes como a diversidade cultural e a alteridade/identidade, a interculturalidade, como perspectiva para a escola e para a educação, possibilita o repensar do próprio modelo de conhecimento que a embasa e é veiculado por ela. A abertura da escola ao diálogo com outras formas de conhecimento, propiciadas pelo contato e pela troca intercultural, pode ser também considerada importante possibilidade para repensar seu papel. 
Em relação a isso, julgamos conveniente destacar um dos últimos diálogos do filme, na cena em que François, na última aula do ano letivo, pede aos alunos que falem sobre o que aprenderam durante o ano.

A fala da aluna Esmeralda, por volta de $1 \mathrm{~h} 57 \mathrm{~min} 84 \mathrm{~s}$, é significativa:

Esmeralda: Não aprendi nada.

François: Não dá pra passar nove meses na escola sem aprender nada. É impossivel.

Esmeralda: A prova está aqui. Eu não aprendi nada.

François: Os livros que lemos, não aprendeu nada com eles?

Esmeralda: São todos chulé.

François: São o quê??

Esmeralda: Porcaria.

François: E algum livro que você escolheu para ler, por exemplo?

Esmeralda: Um livro que eu li? A república. O livro A república.

François: A república, de Platão?

Esmeralda: $E_{\text {... }}$

François: Você leu isso? Como foi ler esse livro?

Esmeralda: $E$ da minha irmã mais velha.

François: Ela estuda Filosofia?

Esmeralda: Não, Direito.

François: Então conte para nós, como é esse livro?

Esmeralda: Bom, tem um cara... Qual o nome?

François: Sócrates.

Esmeralda: Isso, Sócrates. Ele vai parando as pessoas na rua e perguntando: "Tem certeza disso que está pensando? Tem certeza disso que está fazendo?" As pessoas comę̧am a ficar confusas e se questionar. O cara é muito bom.

François: E que tipo de perguntas ele faz? Sobre que assunto?

Esmeralda: Tudo! Sobre amor, religiāo, Deus, sobre as pessoas... Tudo.

François: Que bom que você leu isso!

Esmeralda: $\hat{E}$, eu sei. Não é livro de vagabunda, né?

Por que Esmeralda, uma aluna desinteressada, assim como grande parte dos demais alunos, se interessou pelo livro de Platão? Ao dizer que o livro de Platão fala "sobre tudo! sobre amor, sobre religião, sobre Deus, sobre as pessoas", é possível 
que Esmeralda se refira à necessidade de que a escola e, principalmente, seu currículo - organizado com base nos conhecimentos produzidos pela ciência moderna - dialoguem com outras formas de conhecimento presentes na vivência cotidiana das pessoas.

Neste caso, a referência à filosofia pode apontar para o resgate de práticas fundamentais ao exercício da reflexão, que foram, de certa maneira, perdidas no percurso da construção da ciência moderna (como o distanciamento da poesia, da filosofia e da literatura, por exemplo) e que a escola, por pautar-se nesta forma de conhecimento, acaba reproduzindo. O conjunto de conteúdos trabalhados pela escola a partir de seu currículo parece distante ou faz pouco sentido para a vivência dos alunos, conforme podemos perceber na fala de Esmeralda.

Nesse sentido, finalizando de forma magistral o filme, Cantet sobrepõe duas cenas: a sala de aula vazia, silenciosa, sem vida; o pátio com o jogo de futebol, uma espécie de confraternização entre professores e alunos, que, mesmo em times opostos, interagem, se relacionam — ali está a vida!

\section{Considerações finais}

O cinema, enquanto arte e linguagem, permite e propicia produção de conhecimentos e reflexões sobre a realidade. Além disso, permite e propicia o diálogo com outras formas de produção do conhecimento.

Certamente, a reflexão e a produção de conhecimentos sobre a educação e sobre o papel da escola na atualidade podem ser significativamente enriquecidos com a contribuição do cineasta francês Laurent Cantet no filme Entre os muros da escola.

Sendo assim, neste texto, procuramos discutir alguns elementos, dentre os vários abordados por Cantet em seu filme, que propiciam a reflexão sobre problemáticas como a diversidade cultural e a alteridade/identidade no contexto da escola e da educação.

No entanto, destacamos que o propósito de Cantet, na verdade, não é discutir a escola em si, mas a própria sociedade na qual ela se insere. Repensar o papel da escola nesta sociedade é, de fato, repensar a própria sociedade num momento em que o projeto societário no qual ela foi concebida mostra sinais de esgotamento, conforme apontou Gabriel ${ }^{7}$ (2005, p. 214), já citada neste texto.

Nesse sentido, a escola, tal como se apresenta, é incompatível com as demandas da sociedade atual. Concebida como instituição que construiria uma cidadania

7. A discussão sobre a crise do projeto societário fundado na modernidade é realizada por um conjunto significativo de autores, dentre os quais destacamos a importante contribuição de Boaventura de Sousa Santos. 
universal e homogênea, a escola se vê imersa num contexto de diferenças de várias ordens: religiosa, cultural, sexual, étnica, etc. E esta é uma questão bastante ressaltada por Cantet.

Tendo em vista esta problemática, entendemos que a interculturalidade, como perspectiva para a escola e para a educação, possibilita o repensar do próprio modelo de conhecimento que a embasa e é veiculado por ela. A abertura da escola ao diálogo com outras formas de conhecimento, propiciadas pelo contato e pela troca intercultural, pode ser também considerada importante possibilidade para repensar seu papel.

Dessa forma, o olhar do professor, o papel dos conhecimentos científicos e da hegemonia de uma cultura ocidental devem ser repensados neste momento de (re)definição da escola e seu papel na sociedade.

\section{Referências bibliográficas}

BHABHA, H. K. O local da cultura. Belo Horizonte: Ed. da UFMG, 2005.

CANDAU, V. M. Multiculturalismo e educação: desafios para a prática pedagógica. In: MOREIRA, A. F.; CANDAU, V. M. (Org.). Multiculturalismo: diferenças culturais e práticas pedagógicas. Petrópolis: Vozes, 2008. p. 13-37.

COSTA, M. H. B. V. da. Espaços de subjetividade e transgressão nas paisagens fílmicas. Pro-Posiçōes, Campinas, v. 20, n. 3(60), p. 109-120, set./dez. 2009.

EDUARDO, C. A potência da imagem da impotência. Cinética - cinema e crítica, mar. 2009. Disponível em: <http://www.revistacinetica.com.br/entrelesmurs.htm>. Acesso em: 14 jul. 2010.

FABRIS, E. H. Cinema e Educação: um caminho metodológico. Educação e Realidade, Porto Alegre, v. 33, n. 1, p. 117-134, jan./jun. 2008.

GABRIEL, C. T. A identidade (nacional) na berlinda: uma forma possível de entrar no debate em torno da educação intercultural. In: CANDAU, V. M. Cultura(s) e educação: entre o crítico e o pós-crítico. Rio de Janeiro: DP\&A, 2005. p. 39-72.

GABRIEL, C. T. Conhecimento escolar, cultura e poder: desafios para o campo do currículo em "tempos pós”. In: MOREIRA, A. F.; CANDAU, V. M. (Org.). Multiculturalismo: diferenças culturais e práticas pedagógicas. Petrópolis: Vozes, 2008. p. 212-245.

GUSMÃO, N. M. M. de. Os desafios da diversidade na escola. In: GUSMÃO, N. M. M. de (Org.). Diversidade, cultura e educação: olhares cruzados. São Paulo: Biruta, 2003. p. 83-105.

HISSA, C. E. V. A mobilidade das fronteiras: inserçôes da Geografia na crise da modernidade. Belo Horizonte: Editora da UFMG, 2006.

OLIVEIRA, B. J. de. Cinema e imaginário científico. História, Ciências, Saúde-Manguinhos, Rio de Janeiro, v. 13, p. 133-50, out. 2006. (suplemento). 
QUEIROZ FILHO, A. C. Sobre política e território no espaço da narrativa fílmica. Terra Livre, São Paulo, v. 1, n. 32, p. 47-61, jan./jun. 2009.

SAÇASHIMA, E. "Entre os muros da escola" expõe a visão francesa do choque de civilizações. Cinema UOL, São Paulo, 11 mar. 2009. Disponível em: <http://cinema.uol. com.br/ultnot/2009/03/11/ult4332u1035.jhtm>. Acesso em: 14 jul. 2010.

SOUZA SANTOS, B. de; NUNES, J. A. Introdução: para ampliar o cânone do reconhecimento, da diferença e da igualdade. In: SOUZA SANTOS, B. de. (Org.). Reconhecer para libertar. Os caminhos do cosmopolitismo multicultural. Rio de Janeiro: Civilização Brasileira, 2003. p. 13-59.

TEDESCHI, L. A. Interculturalidade: igualdade e diferença em debate. In: TEDESCHI, L. A. et al. (Org.) Abordagens interculturais. Porto Alegre: Martins Livreiro-Editor, 2008. p. 11-21.

WERNECK, V. R. Uma avaliação sobre a relação multiculturalismo e educação. Ensaio: avaliação e políticas públicas em educação. Rio de Janeiro, v. 16, n. 60, p. 413-436, jul./set. 2008.

Recebido em 12 de agosto de 2010 e aprovado em 27 de maio de 2011. 
